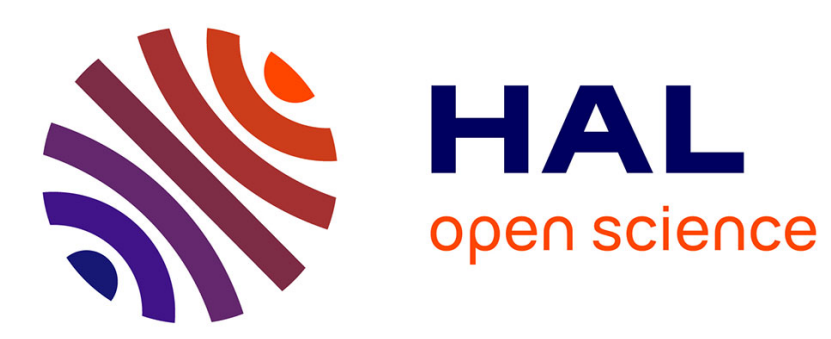

\title{
Copper electrodeposition under a weak magnetic field: effect on the texturing and properties of the deposits
}

S. V Kovalyov, B Girin, C. Debiemme-Chouvy, V. I Mishchenko

\section{To cite this version:}

S. V Kovalyov, B Girin, C. Debiemme-Chouvy, V. I Mishchenko. Copper electrodeposition under a weak magnetic field: effect on the texturing and properties of the deposits. Journal of Applied Electrochemistry, 2021, 51 (2), pp.235-243. 10.1007/s10800-020-01492-3 . hal-03450519

\author{
HAL Id: hal-03450519 \\ https://hal.science/hal-03450519
}

Submitted on 26 Nov 2021

HAL is a multi-disciplinary open access archive for the deposit and dissemination of scientific research documents, whether they are published or not. The documents may come from teaching and research institutions in France or abroad, or from public or private research centers.
L'archive ouverte pluridisciplinaire HAL, est destinée au dépôt et à la diffusion de documents scientifiques de niveau recherche, publiés ou non, émanant des établissements d'enseignement et de recherche français ou étrangers, des laboratoires publics ou privés. 


\title{
Copper electrodeposition under a weak magnetic field: Effect on the texturing and properties of the deposits.
}

\author{
S.V. Kovalyov*a , O.B. Girin ${ }^{\mathrm{a}}$, C. Debiemme-Chouvy ${ }^{\mathrm{b}}$, V.I. Mishchenko ${ }^{\mathrm{a}}$ \\ ${ }^{a}$ Ukrainian State University of Chemical Technology, Dnipro, Ukraine \\ ${ }^{b}$ Laboratoire Interfaces et Systèmes Electrochimiques (UMR 8235),Sorbonne Université, CNRS, Paris, France
}

\begin{abstract}
The effect of a weak magnetic field (induction of 0.5 to $0.7 \mathrm{mT}$ ) on the electrodeposition process and the formation of crystallographic texture, morphology and properties of copper deposits have been considered. Electrodeposition studies were performed using cyclic voltammetry, chronoamperometry, and chronopotentiometry. X-ray texture analysis and scanning electron microscopy observations were used to study the texture and the morphology of the copper deposits. Some of their properties were obtained by measuring their microhardness and reflectivity. The effects of decreasing the rate of copper electrodeposition, enhancing texture formation and refinement of grain aggregates of the surface of copper films under the influence of a weak magnetic field have been evidenced. The interrelation of the texture and morphology of the copper electrodeposit surface with their microhardness and reflectivity have been revealed. The conditions for obtaining copper deposits with enhanced microhardness and reflectivity have been determined. It is shown that the electrochemical deposition with a weak magnetic field is a promising direction for obtain materials with desired properties, without using strong magnetic fields and adding surfactants to the electrolyte.
\end{abstract}

Keywords: electrodeposition, magnetic field, copper, texture, surface morphology, microhardness, reflectivity.

\footnotetext{
${ }^{*}$ Corresponding author: S.V. Kovalyov. Ukrainian State University of Chemical Technology, Gagarin av., 8, Dnipro, Ukraine, 49005.

E-mail addresses: S.V. Kovalyov sv kovalyov@i.ua (https://orcid.org/0000-0002-5115-1584), O.B. Girin girin@ua.fm (https://orcid.org/0000-0001-7712-2290), C. Debiemme-Chouvy catherine.debiemmechouvy@sorbonne-universite.fr (https://orcid.org/0000-0001-7171-6039), V.I. Mishchenko vlada@ua.fm.
} 


\section{Introduction}

A significant number of publications have been devoted to studying the effect of a magnetic field on the electrodeposition and structure formation of copper films [1-13]. This is due to the fact that copper deposits, electrodeposited under the influence of a magnetic field, exhibit enhanced characteristics of their properties. According to the data reported in [1], the use of a magnetic field of $1.2 \mathrm{~T}$ during copper electroreduction leads to a decrease in overpotential and an increase in the deposition rate of copper. According to the data obtained by Fattahi and Bahrolloom [2], by using a pulse plating process combined with a magnetic field of 0.12-0.24 T, copper deposits with a finer grain can be obtained.

A number of publications [3-6] attribute the improvement in the quality of copper deposits to the influence of a strong magnetic field (induction of 0.25 to $1 \mathrm{~T}$ ). However, as noted in Ref. [7], the influence of a magnetic field on the deposition rate of copper becomes noticeable only when using a magnetic field with induction above $4 \mathrm{~T}$.

In addition, some authors question the influence of a magnetic field both up to $10 \mathrm{~T}$ [8] and less than $0.5 \mathrm{~T}$ [9] on the process of copper (II) electroreduction. There is also an ambiguous opinion about the influence of a magnetic field on the rate of the process of copper electrodeposition [10].

It should be noted that in all the above papers, the induction of the magnetic field has values higher than 60 $\mathrm{mT}$. Information about the effect of weak magnetic field (less than $1 \mathrm{mT}$ ) on the processes of electrocrystallization of metals, and in particular of copper, is completely absent in the literature. We obtained the first data on the effect of a weak magnetic field on the electrodeposition of metals (tin), these findings are reported in [14].

In connection with the above, the main goal of this work was to identify the influence of weak magnetic fields $(0.5$ to $0.7 \mathrm{mT})$ on electroreduction, texturing and properties of copper deposits. Given the negative environmental impact of strong magnetic fields and surfactants introduced into the electrolytes, this work seems to be relevant.

\section{Experimental details}

Copper was electrodeposited in an electrolyte of composition, $\mathrm{CuSO}_{4} \cdot 5 \mathrm{H}_{2} \mathrm{O} 0.8 \mathrm{M}$ and $\mathrm{H}_{2} \mathrm{SO}_{4} 0.4 \mathrm{M}$ at a temperature of $25 \pm 2^{\circ} \mathrm{C}$. The applied cathodic current density was either 10 or 40 or $70 \mathrm{~mA} / \mathrm{cm}^{2}$. These current densities were chosen in order to obtain smooth deposits with a current efficiency of about 100\%. Compressed air was used in some experiments in order to stir the electrolyte.

The electrochemical cell was placed, according to the method described in [15], in a constant magnetic field of either 0.5 or 0.6 or $0.7 \mathrm{mT}$ (Fig. 1). A silver chloride electrode (Ag/AgCl) filled with a saturated $\mathrm{KCl}$ solution 
was used as the reference electrode. Copper or platinum plates were used as the material of the working electrode (WE), the counter electrode was copper sheet or platinum grid.

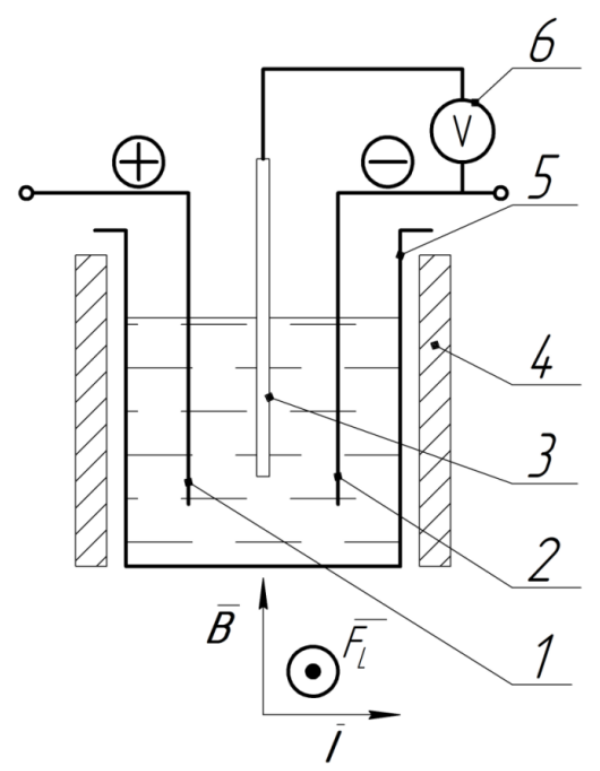

Fig. 1. Cell for electrodeposition of copper under a magnetic field: 1 - anode; 2 - cathode (WE); 3 reference electrode; 4 - the source of the magnetic field; 5 - glass cell; 6 - measuring equipment. The diagram shows the direction vectors of the magnetic induction $(B)$, current $(I)$ and Lorentz force $\left(F_{L}\right)$ (to the observer).

X-ray texture analysis of the electrodeposited copper samples was performed according to the method described in [16] using an automated and modernized X-ray diffractometer DRON-2. The texture of the electrodeposits was determined by the combination of straight pole figures [17]. The degree of texturing of the electrodeposits was quantified using the average angle of scattering of the axial component of the texture ( $\alpha$ values were determined in degrees) and the proportion of grains with a disordered orientation ( $\varepsilon$ values were determined in relative units, taking the completely disordered component as a unit).

The morphology of the copper coating surface was studied by scanning electron microscopy (SEM-106I) using the secondary electron imaging mode. The limiting residual pressure in the microscope column (in the gun region) did not exceed $6.7 \cdot 10^{-4} \mathrm{~Pa}$, the gun current was $80 \mathrm{~mA}$.

The parameters of microhardness and reflectivity were chosen as the physic-mechanical characteristics of the copper deposits. The microhardness of the samples was measured with a PMT-3 microhardness meter. The reflectivity of the deposits was evaluated using a photoelectric gloss meter FB-2; the standard was black-violet glass, the reflectivity of which was taken as $65 \%$.

An analysis of the physic-mechanical properties of the deposits was performed using the full-factor experiment $2^{2}$ ("so called" the $2^{2}$ factorial designs) [18]. Microhardness and reflectivity of the deposits formed under 
a cathodic current density of 10,40 and $70 \mathrm{~mA} / \mathrm{cm}^{2}$ and inductance of the magnetic field of $0.5,0.6$ and $0.7 \mathrm{mT}$ served as data for analysis. The adequacy of the obtained mathematical models was verified by Fisher criterion.

\section{Results and discussion}

In order to prove the influence of a weak magnetic field $(0.5-0.7 \mathrm{mT})$ on the process of electrodeposition of copper, the study was conducted using various methods such as cyclic voltammetry, chronoamperometry and chronopotentiometry.

The experimental data of copper electrodeposition process, which were obtained by chronopotentiometry at a current density of $-10 \mathrm{~mA} / \mathrm{cm}^{2}$ with varying induction of the magnetic field, are presented in Fig. 2. At this current density, no significant differences were observed on the electrode potential (the difference between them did not exceed $20 \mathrm{mV}$ ). Only a slightly higher potential was observed when the magnetic field of $0.5 \mathrm{mT}$ was applied. However, the shape of the curve obtained by stirring the electrolyte indicates a slight decrease in potential during beginning of the electrodeposition process (see curve 3 in Fig. 2).

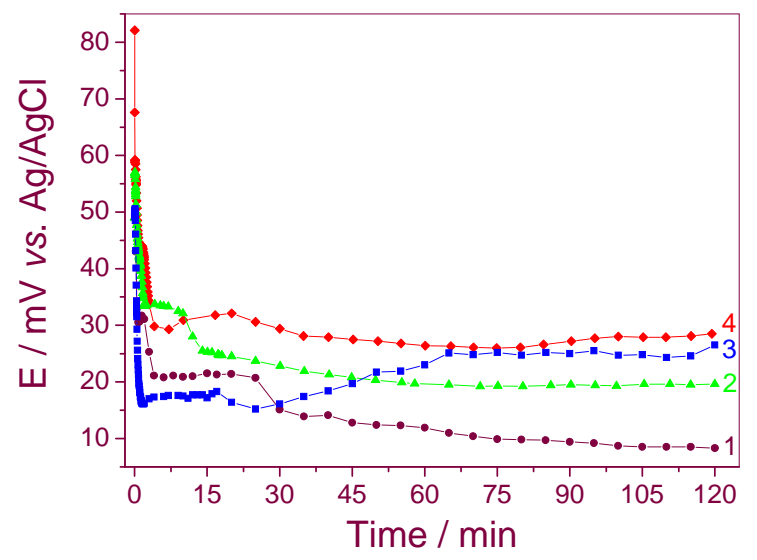

Fig. 2. Chronopotentiograms obtained at a copper electrode at a current density of $-10 \mathrm{~mA} / \mathrm{cm}^{2}$ in a magnetic field of (1) $0.5 \mathrm{mT}$ and (4) $0.7 \mathrm{mT}$; (2) without magnetic field; (3) without magnetic field and with the electrolyte being stirred.

As known in reaction (1), 2 electrons take part in the process of copper reduction. Thus, using Faraday's law, for a current density of $10 \mathrm{~mA} / \mathrm{cm}^{2}$ applied during 120 minutes, the thickness of the copper deposit could be estimated to $26 \mu \mathrm{m}$ (with a current efficiency of $100 \%$ and $\mathrm{d}_{\mathrm{Cu}}=8.96 \mathrm{~g} / \mathrm{cm}^{3}$ ).

$$
\mathrm{Cu}^{2+}+2 \mathrm{e}^{-} \rightarrow \mathrm{Cu}
$$

Chronopotentiograms obtained for applied current density of $-70 \mathrm{~mA} / \mathrm{cm}^{2}$ showed that overpotential copper reduction increases under the impact of a magnetic field (Fig. 3). The highest value of the overpotential was observed 
for a magnetic induction of $0.5 \mathrm{mT}$. It exceeded by more than $100 \mathrm{mV}$ the value observed during the copper electroreduction in the absence of a magnetic field. The electrode overpotential was lower under a magnetic field of $0.7 \mathrm{mT}$ than under $0.5 \mathrm{mT}$, though it was by $30 \mathrm{mV}$ higher compared to the electrode potential during the deposition without applied magnetic field.

A weak magnetic field probably does not cause electrolyte stirring, as indicated by an increase in the overvoltage of copper electrodeposition (this follows from a comparison of curves 2 and 4 in Fig. 3).

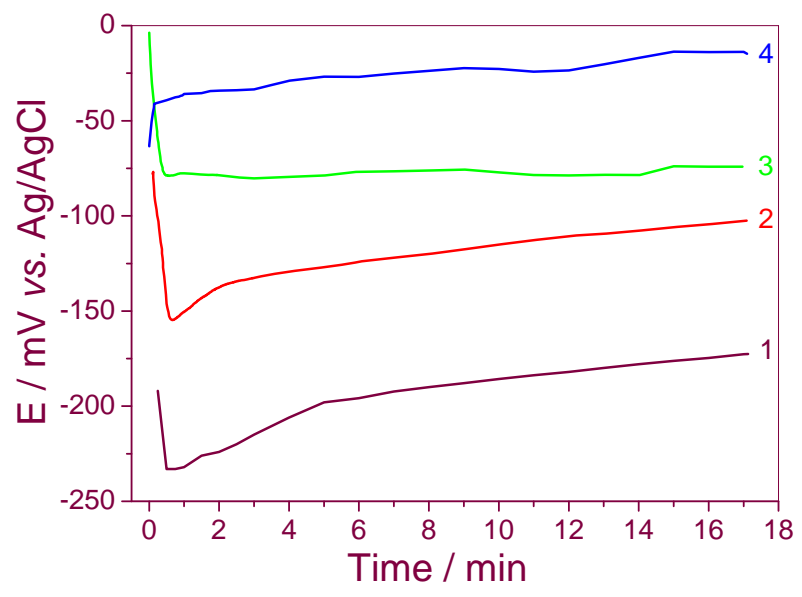

Fig. 3.Chronopotentiograms obtained at a copper electrode at a current density of $-70 \mathrm{~mA} / \mathrm{cm}^{2}$ in a magnetic field with an induction of (1) $0.5 \mathrm{mT}$; (2) $0.7 \mathrm{mT}$; (3) without magnetic field; (4) without magnetic field and with the electrolyte being stirred.

The chronopotentiometry data are supplemented with the results obtained using the chronoamperometry method. Fig. 4 shows copper deposition curves obtained at different electrode potentials and magnetic field induction. 

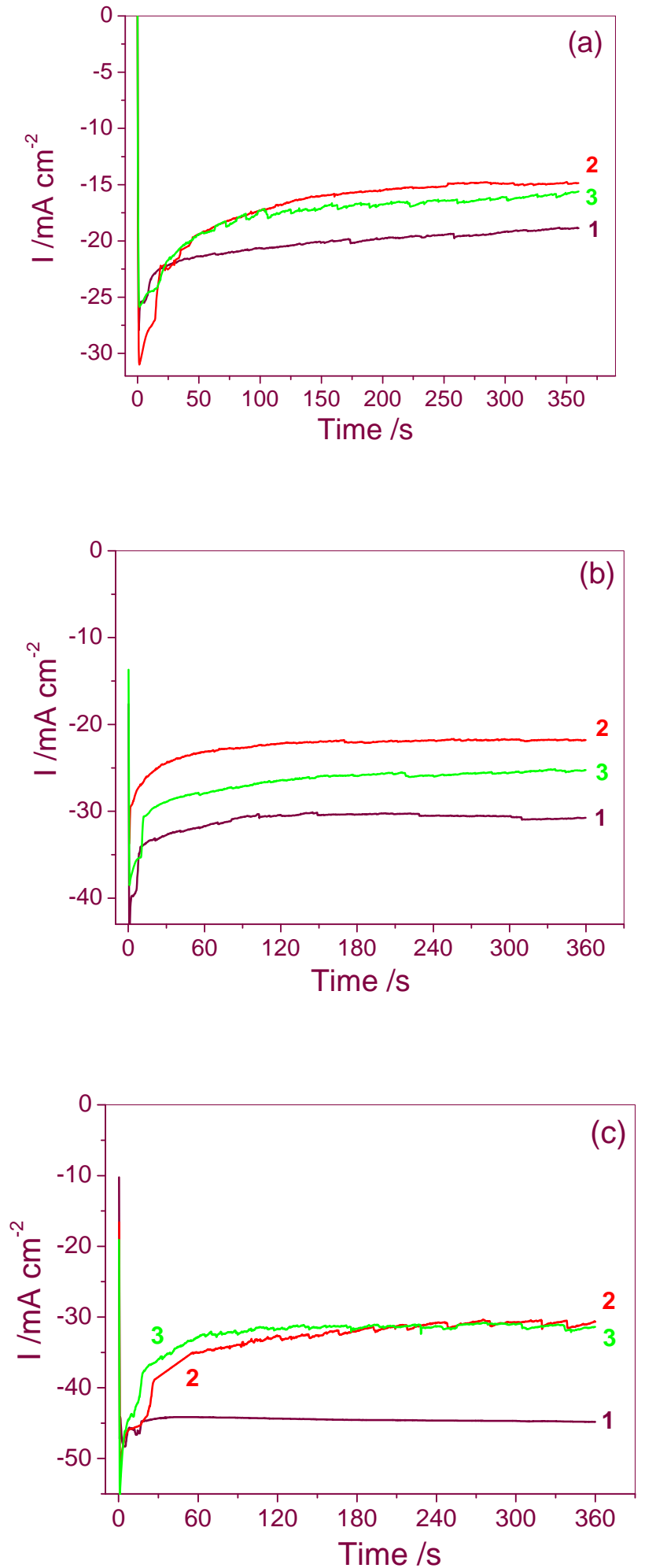

Fig. 4.Chronoamperograms of copper deposition on copper electrode at applied potentials of (a)-0.15 V; (b) $-0.2 \mathrm{~V}$; (c) $-0.25 \mathrm{~V}$ and magnetic induction of (1) 0 ; (2) $0.5 \mathrm{mT}$; (3) $0.7 \mathrm{mT}$.

As expected, chronoamperograms reported in Fig. 4 show an increase in the copper electroreduction rate with decreasing the applied potential. However, when a magnetic field was applied, the rate of the process decreased 
at all the potentials tested. The most significant decrease in the copper reduction rate was observed when a magnetic field of $0.5 \mathrm{mT}$ was applied (for all the potentials used).

Thus, chronoamperograms confirmed the data obtained by chronopotentiometry and provided additional evidence of a decrease in the rate of copper electroreduction under the conditions of exposure to a weak magnetic field.

The cyclic voltammograms shown in Fig. 5 were obtained on platinum electrode at various potential scan rates $(5$ to $50 \mathrm{mV} / \mathrm{s})$. For all the scan rates when a magnetic field was applied, a decrease in current density was observed. For a magnetic field induction of $0.5 \mathrm{mT}$, the current density was the smallest (although there was not much difference between the curves obtained with a magnetic field of 0.5 and $0.7 \mathrm{mT}$ ).

On the cyclic voltammograms, as well as on the chronopotentio- and chronoamperograms, a decrease in the rate of the process was observed when a magnetic field was applied. At the same time, the difference in the process rate for different values of the magnetic field induction is much less than for electrodeposition performed without a magnetic field. The copper deposition rate was the lowest under a magnetic field of $0.5 \mathrm{mT}$.
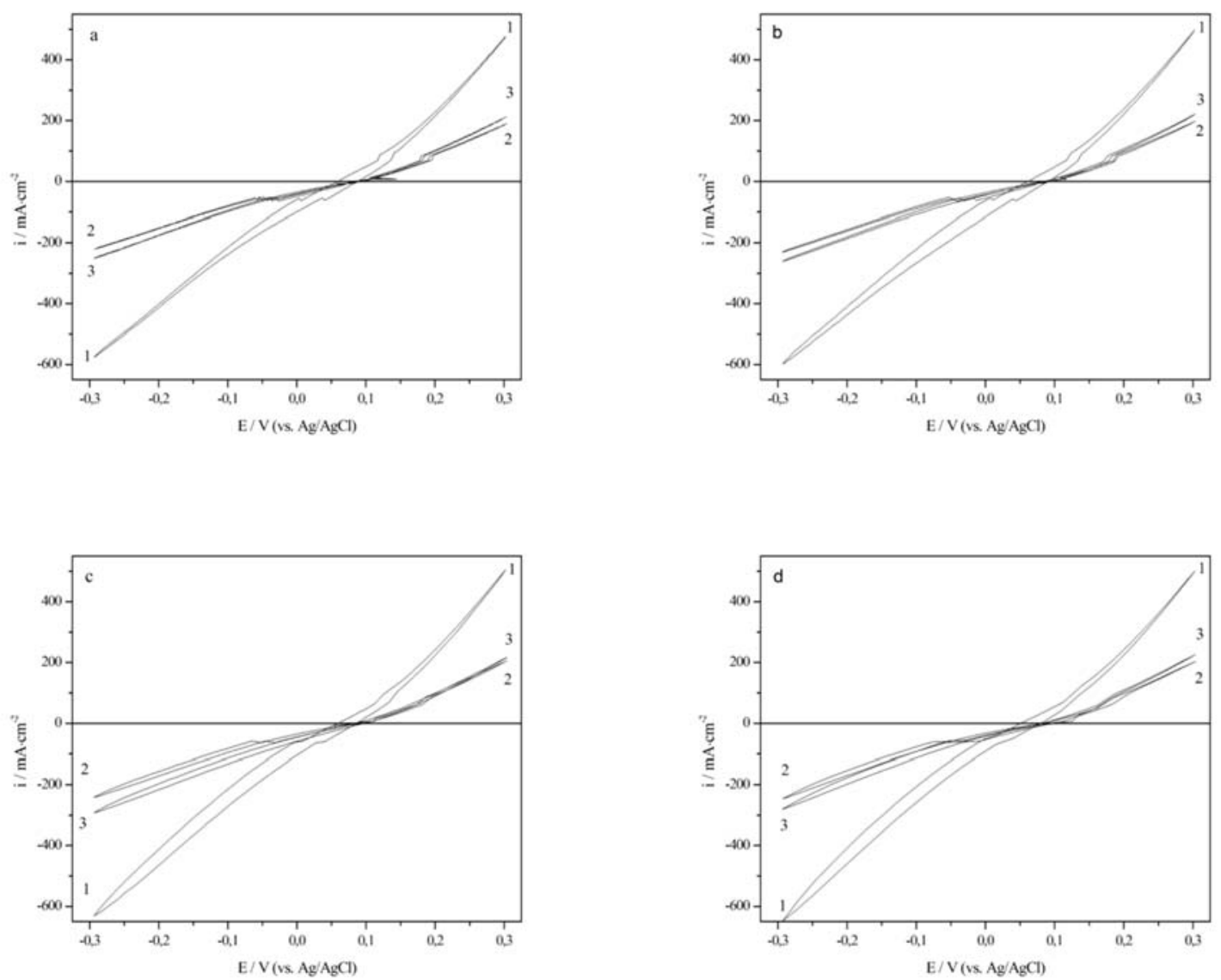

Fig.5. $\mathrm{CV}$ responses in $\mathrm{CuSO}_{4} \cdot 5 \mathrm{H}_{2} \mathrm{O} 0.8 \mathrm{M}^{2}$ and $\mathrm{H}_{2} \mathrm{SO}_{4} 0.4 \mathrm{M}$ solution at platinum electrode at various scan rates: (a) $5 \mathrm{mV} / \mathrm{s}$;(b) $10 \mathrm{mV} / \mathrm{s}$; (c) $25 \mathrm{mV} / \mathrm{s}$; (d) $50 \mathrm{mV} / \mathrm{s}$ and magnetic induction: (1) 0; (2) $0.5 \mathrm{mT}$; (3) $0.7 \mathrm{mT}$. 
According to the results of X-ray texture analysis, the copper electrodeposits without a magnetic field are characterized by the absence of any preferential grain orientation, i.e. the grains are randomly oriented. This result is in contradiction with the data reported in Ref. [19], in which, based on a comprehensive analysis of the texture, substructure and surface morphology of copper electrodeposits formed in a copper sulfate solution, they revealed the main preferential orientation of the grains - the axial texture with the [110] axis, as well as additional orientations of grains with axes [100] and [211] $+[310]$, depending on the $\mathrm{Cu}(\mathrm{II})$ reduction conditions.

The electrochemical reduction of copper in the presence of a magnetic field was accompanied by the appearance of an axial texture, the axis of which depended on the current density. Thus, the texture of copper deposits obtained at a current density of $-10 \mathrm{~mA} / \mathrm{cm}^{2}$ under a magnetic field of $0.5 \mathrm{mT}$ was characterized by an axial component with an [110] axis perpendicular to the surface of the deposits, and a disordered component (Fig. 6a).
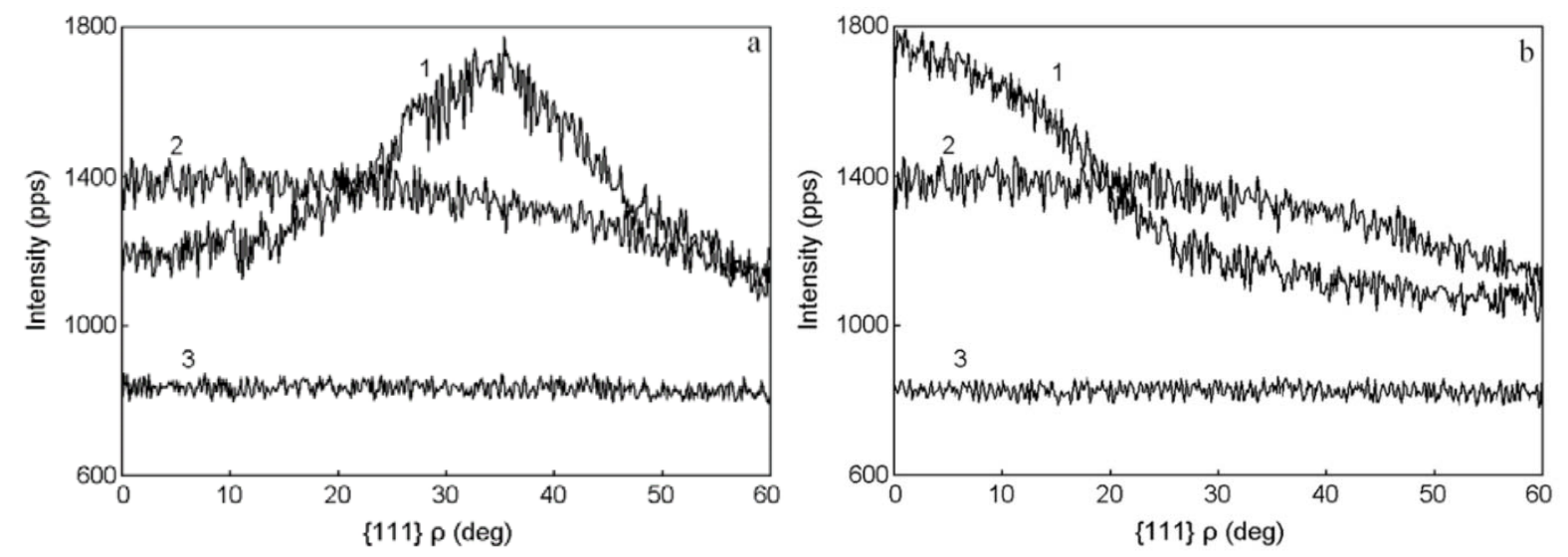

Fig. 6. Textural curves of copper electrodeposits obtained at a current density of (a) $-10 \mathrm{~mA} / \mathrm{cm}^{2}$ and (b) $70 \mathrm{~mA} / \mathrm{cm}^{2}$ under the influence of a magnetic field of $0.5 \mathrm{mT}$. (1) and (2) are the curves of the texture record of interference $\{111\}$ of the sample and the standard, respectively; (3) background line.

Indeed, the presence of a textural maximum of the axial orientation with the [110] axis at an angle of $35.3^{\circ}$ on the pole figure (111) of the electrodeposited copper (Fig. 7a) allowed us to draw this conclusion. And the textural maxima of the axial orientation with the axis [110] at angles of 0 and $60^{\circ}$ on the pole figure (220) validated it. 

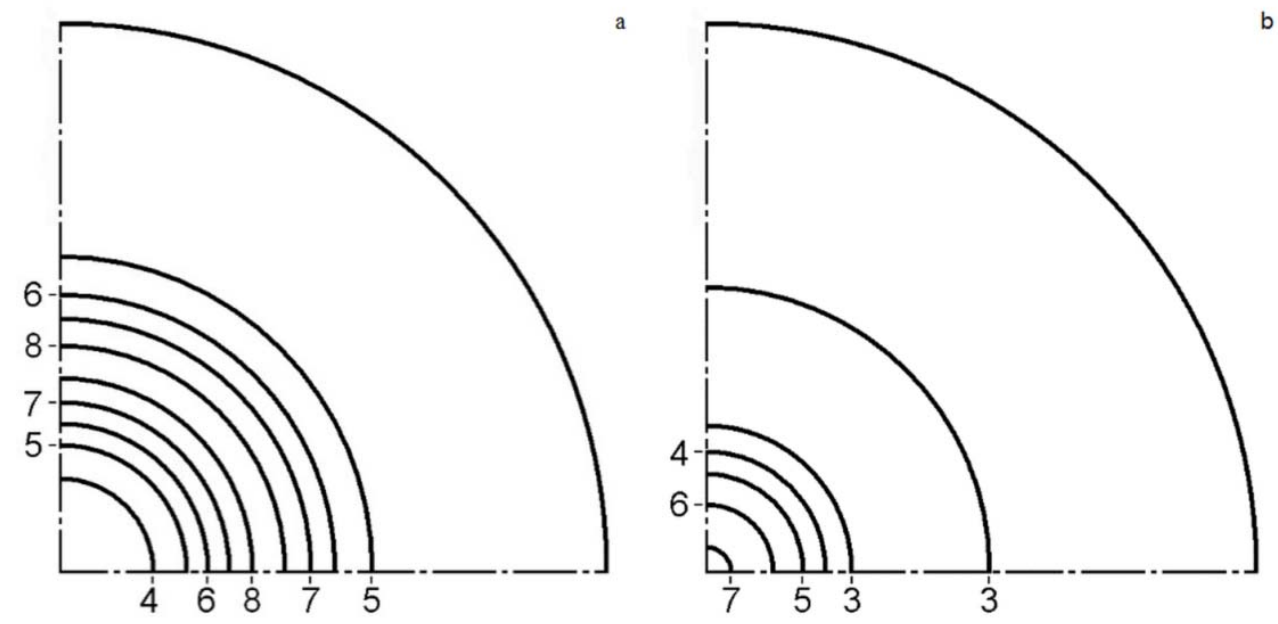

Fig. 7. Direct pole figures (111) of copper, electrodeposited at a current density of (a) $-10 \mathrm{~mA} / \mathrm{cm}^{2}$ and (b) $-70 \mathrm{~mA} / \mathrm{cm}^{2}$ under the influence of a magnetic field of $0.5 \mathrm{mT}: 3-8$ - levels of the same intensity of X-ray diffraction.

Fig. $6 \mathrm{~b}$ indicates that the formation of a copper deposit at an increased current density $\left(-70 \mathrm{~mA} / \mathrm{cm}^{2}\right)$ with the same magnetic induction $(0.5 \mathrm{mT})$ was accompanied by the appearance of a texture, which was described by an axial component with the [111] axis perpendicular to the surface of the deposits and a random component. Component [111] was identified on the basis of the presence of a textural maximum of axial orientation with axis [111] at an angle of $0^{\circ}$ on the pole figure (111) of the electrodeposited copper (Fig. 7b). The presence of the textural maximum of the axial orientation with the [111] axis at an angle of 35.3 degrees on the pole figure (220) confirmed the conclusion made.

A quantitative analysis of the degree of texturing of the copper deposits showed that the most perfect axial texture is formed in the deposits obtained with induction of $0.5 \mathrm{mT}$. Indeed, the average angle of scattering of the axial orientation with the [110] axis was $11.0^{\circ}$, and the proportion of grains with a random component of the texture was 0.62 rel. units. In other words, $38 \%$ of the grains were oriented $\{110\}$ by the crystallographic plane almost parallel to the surface of the deposit (with an average angle of deviation of grains from the normal to the $\{110\}$ plane, equal to $11.0^{\circ}$ ). With an increase of the magnetic field to $0.7 \mathrm{mT}$, a slight scattering of the texture was observed.

A similar feature in changing the degree of texture was also revealed in the preferential orientation of the crystal lattices of copper deposit grains in the [111] direction. Here, the smallest values of the axial orientation characteristics with the [111] axis were established for the deposits obtained with an induction of $0.5 \mathrm{mT}$ (the angle $\alpha$ was $16.1^{\circ}$ and the fraction $\varepsilon$ was 0.69 relative units). With an increase in magnetic field induction up to $0.7 \mathrm{mT}$, the values of the above texture characteristics sharply increased, which indicated scattering of the axial texture with the [111] axis. 
It should be noted that in the face centered cubic (FCC) structure, which copper deposits exhibit, the $\{111\}$ plane is the most close-packed. Therefore, the formation of an axial texture with the [111] axis in copper deposits should lead to a significant increase in their microhardness, corrosion resistance, wear resistance and other physicmechanical characteristics.

Since the properties of the deposits are influenced not only by the texture, but also by the morphology of the surface, scanning electron microscopy observations of the surface of the copper deposits were conducted. The micrographs presented in Fig. 8 do evidence that when a magnetic field is applied, the morphology of the deposits changed drastically.
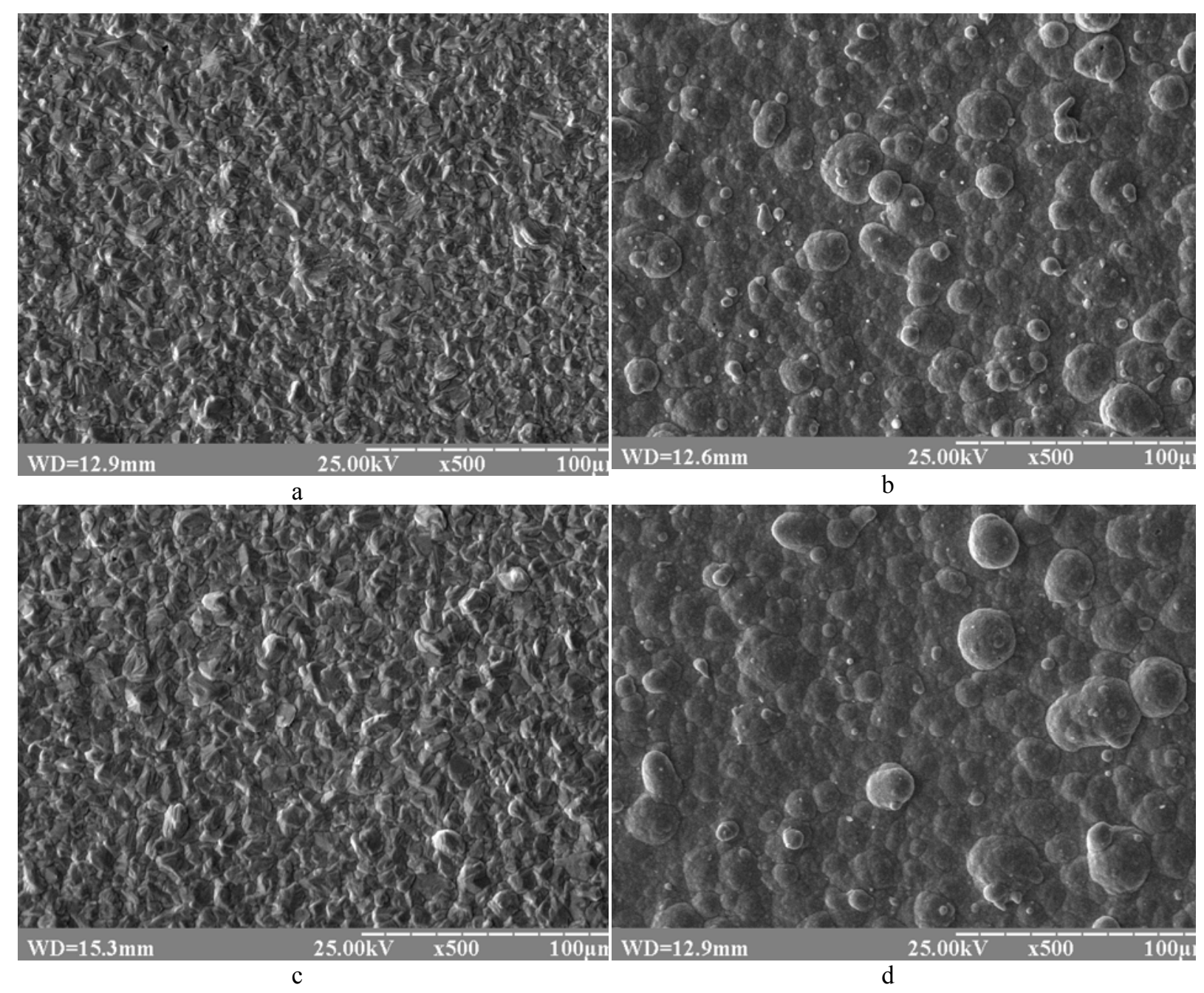


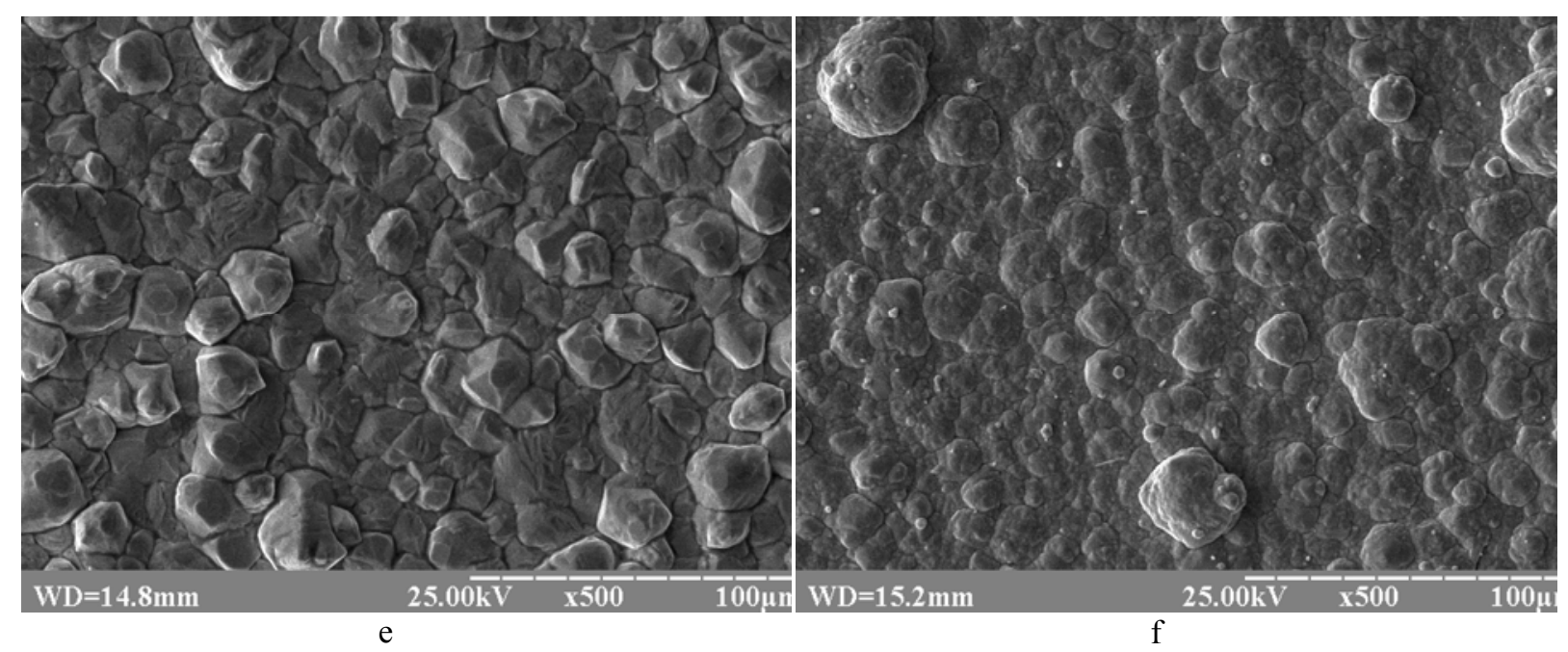

Fig.8. SEM micrographs of the copper films, electrodeposited under the conditions: (a) $-10 \mathrm{~mA} / \mathrm{cm}^{2}$ and $0.5 \mathrm{mT}$; (b) $-70 \mathrm{~mA} / \mathrm{cm}^{2}$ and $0.5 \mathrm{mT} ;$ (c) $-10 \mathrm{~mA} / \mathrm{cm}^{2}$ and $0.7 \mathrm{mT} ;(\mathrm{d})-70 \mathrm{~mA} / \mathrm{cm}^{2}$ and $0.7 \mathrm{mT} ;(\mathrm{e})-10 \mathrm{~mA} / \mathrm{cm}^{2}$ and $0 \mathrm{mT}$; (f) $-70 \mathrm{~mA} / \mathrm{cm}^{2}$ and $0 \mathrm{mT}$.

Thus, copper deposits obtained without exposure to a magnetic field (Fig. 8e and 8f) featured larger surface formations of grains that had both a facet (Fig. 8e) and a spherical shape (Fig. 8f). The deposits obtained under a magnetic field were about one-fifth of grain aggregate sizes, which testified to the refinement of the structure. The detected feature is particularly evident when comparing SEM micrographs of electrodeposits obtained at a current density of $-10 \mathrm{~mA} / \mathrm{cm}^{2}$ under the influence of a magnetic field of $0.5 \mathrm{mT}$ (Fig. 8a) or $0.7 \mathrm{mT}$ (Fig. 8c) with a SEM micrograph of the deposit obtained in the same mode, but in the absence of a magnetic field (Fig. 8e).

Naturally, it should be expected that such a refinement of the structure of the surface layers of copper deposits affect their reflectivity. Indeed, the smaller the surface aggregates of the grains, the lower the attenuation or absorption of the reflected light rays and the higher the surface reflectivity should be.

Based on the analysis of microhardness measurements of copper deposits obtained at current densities of $10,-40$ and $-70 \mathrm{~mA} / \mathrm{cm}^{2}$ and magnetic field induction of $0.5,0.6$ and $0.7 \mathrm{mT}$, the following regression equation was obtained:

$$
H=-678.3+133.6 \cdot i+2307 \cdot B-186.2 \cdot i \cdot B
$$

where $H$ is the microhardness of the deposit, in $\mathrm{MPa}, i$ is current density, in $\mathrm{mA} / \mathrm{cm}^{2}, B$ is magnetic field induction, in $\mathrm{mT}$.

Equation (2) and the response surface constructed on the basis of this data (Fig. 9a) show that an increase in the current density and magnetic induction leads to a slight increase in the microhardness of the deposit, whereas a decrease in the magnetic induction and a combined increase in the current density, on the contrary, greatly increase its microhardness. 


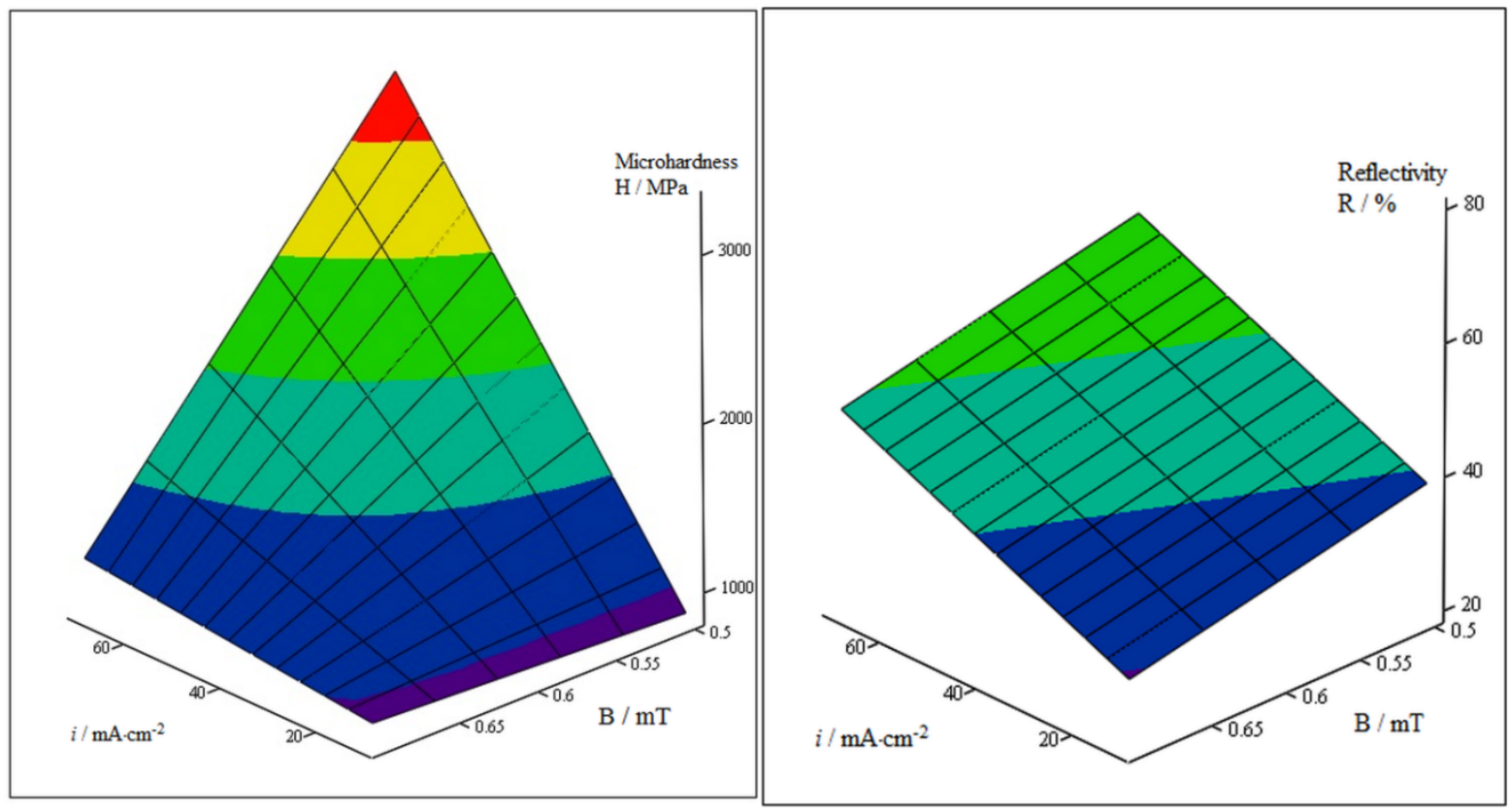

Fig. 9. Graphs of response surfaces constructed using (a) equation (2)and (b) equation (3).

With a current density of $-70 \mathrm{~mA} / \mathrm{cm}^{2}$ and a magnetic field induction of $0.5 \mathrm{mT}$, the maximum deposit microhardness of $3310 \mathrm{MPa}$ was observed, which significantly exceeded the microhardness values (590-1470 MPa) given in [20]. It should be noted that the microhardness of the copper substrate on which the deposits were formed was $750 \mathrm{MPa}$.

Therefore, the assumption of an increase in the microhardness of copper deposits due to the formation of an axial texture with the [111] axis was fully confirmed. Obviously, the refinement of grain surface formations made a certain contribution to the increase in the microhardness of the copper deposits.

Also, the assumption of the relationship between the surface morphology and reflectivity of copper deposits was validated. Indeed, after processing the experimental data of reflectivity of the copper deposits obtained at current densities of $-10,-40$ and $-70 \mathrm{~mA} / \mathrm{cm}^{2}$ and magnetic field induction of $0.5,0.6$ and $0.7 \mathrm{mT}$, the following regression equation was obtained:

$$
R=59.86+0.3271 \cdot i-48.13 \cdot B
$$

where $R$ is the reflectivity of the deposit in $\%, i$ is the current density in $\mathrm{mA} / \mathrm{cm}^{2}$ and $B$ the magnetic field induction in $\mathrm{mT}$.

Analysis of the regression equation (3) and graphic data (Fig. 9b) indicate that the reflectivity of the deposit tends to increase with a decrease of the magnetic field induction and increase applied current density. The highest reflectivity was obtained at a current density of $-70 \mathrm{~mA} / \mathrm{cm}^{2}$ and a magnetic field induction of $0.5 \mathrm{mT}$, i.e. in a mode of obtaining deposits, which provided the most fine-grained and smoothed surface morphology. In this case, the value of the Fisher criterion was 1.03 , which is lower than the tabular one of 3.11 at a significance level of 0.1 . 
Thus, the interrelation of the texture and morphology of the copper electrodeposits with their microhardness and reflectivity have been revealed, and the conditions for obtaining copper electrodeposits with increased microhardness and reflectivity have been determined.

\section{Conclusions}

1. It has been established that a weak magnetic field of 0.5 to $0.7 \mathrm{mT}$ created inside an electrochemical cell affects the electrodeposition process, texture, morphology and properties of copper deposits.

2. The effects of reducing the rate of copper electrodeposition, enhancing texture formation and refinement of grain aggregates of the surface of copper deposits under the influence of a weak magnetic field of 0.5 to $0.7 \mathrm{mT}$ have been found.

3. The interrelation of the texture and morphology of the surface of copper electrodeposits with their microhardness and reflectivity has been revealed.

4. The conditions for obtaining copper electrodeposits with increased microhardness (about $3000 \mathrm{MPa}$ ) and reflectivity (about 50\%) have been determined: magnetic field induction of $0.5 \mathrm{mT}$ and current density of $70 \mathrm{~mA} / \mathrm{cm}^{2}$.

5. It has been proposed to use galvanomagnetic finish of materials and products in a weak magnetic field ( 0.5 to $0.7 \mathrm{mT}$ ), which will improve the properties of the electrodeposits and exclude the use of strong magnetic fields and surfactant additives from the electrochemical process.

\section{References}

[1] Noninski VC (1997) Magnetic field effect on copper electrodeposition in the Tafel potential region. Electrochim. Acta 42:251-254.

[2] Fattahi A, Bahrololoom ME (2015) Investigating the effect of magnetic field on pulse electrodeposition of magnetic and non-magnetic nanostructured metals. Surface and Coatings Technology 261:426-435. https://doi = $\{10.1016 /$ j.surfcoat.2014.10.013

[3] König J, Tschulik K, Büttner L, Uhlemann M, Czarske J (2013) Analysis of the electrolyte convection inside the concentration boundary layer during structured electrodeposition of copper in high magnetic gradient fields. Anal. Chem. 85:3087-3094.https://dx.doi.org/10.1021/ac302601t

[4] Bund A, Koehler S, Kuehnlein HH, Plieth W(2003) Magnetic field effects in electrochemical reactions. Electrochim. Acta 49:147-152.https://doi:10.1016/j.electacta.2003.04.009. 
[5] Yang X, Eckert K, Seidel K, Uhlemann M (2008) The start-up of natural convection during copper electrolysis in the presence of an opposing Lorentz force. Electrochim. Acta. 54:352-359. https://doi:10.1016/j.electacta.2008.07.074.

[6] Tschulik K, Koza JA, Uhlemann M, Gebert A, Schultz L (2009) Effects of well-defined magnetic field gradients on the electrodeposition of copper and bismuth. Electrochem. Comm. 11:2241-2244. https://doi:10.1016/j.elecom.2009.09.041.

[7] Sugiyama A, Hashiride M, Morimoto R, Nagai Y, Aogaki R (2004) Application of vertical micro-disk MHD electrode to the analysis of heterogeneous magneto-convection. Electrochim. Acta 49:5115-5124. https://doi:10.1016/j.electacta.2004.06.024.

[8] Matsushima H, Ispas A, Bund A, Bozzini B (2008) Magnetic field effects on the initial stages of electrodeposition processes. J. Electroanal. Chem. 615:191-196. https://doi:10.1016/j.jelechem.2007.12.010.

[9] Matsushima H, Bund A, Plieth W, Kikuchi S, Fukunaka Y (2007) Copper electrodeposition in a magnetic field. Electrochim. Acta 53:161-166. https://doi:10.1016/j.electacta.2007.01.043.

[10] Fernandez D, Coey JMD (2009) Inhomogeneous electrodeposition of copper in a magnetic field. Electrochem. Comm. 11:379-382. https://doi:10.1016/j.elecom.2008.10.057.

[11] Labchir N, Hannour A, Vincent D, Hssi AA, Ihlal A, Sajieddine M (2019) Magneto-electrodeposition of granular $\mathrm{Co}-\mathrm{Cu}$ nanowire arrays. Mater. Res. Express6:1150c3 (9 pages). https://doi.org/10.1088/2053$1591 / \mathrm{ab} 4 \mathrm{~d} 5 \mathrm{a}$

[12] Huang M, Marinaro G, Yang X, Fritzsche B, Lei Z, Uhlemann M, Eckert K, Mutschke G (2019) Mass transfer and electrolyte flow during electrodeposition on a conically shaped electrode under the influence of a magnetic field. J. Electroanal. Chem.842:203-213.

[13] Murdoch HA, Yin D, Hernández-Rivera E, Giri AK (2018) Effect of applied magnetic field on microstructure of electrodeposited copper. Electrochem. Comm. 97 :11-15. https://doi.org/10.1016/j.elecom.2018.09.013

[14] Kovalyov SV, Girin OB, Debiemme-Chouvy C (2018) Properties of tin films electrodeposited under a weak magnetic field. Surface Engineering and Applied Electrochemistry.54:593-598. https://doi:10.3103/S1068375518060066.

[15] Kovalyov SV, Girin OB, Kosolapov AO. Patent 199771 Ukraine. Method for the electrochemical production of deposit in a magnetic field.(In Ukrainian).

https://base.uipv.org/searchINV/search.php?action=viewdetails\&IdClaim=261033.

[16] Girin OB, Vorob'ev GM. Patent 1629828 Ros. Federation. The method of x-ray diffractometric analysis of textured materials. (In Russian). 
https://worldwide.espacenet.com/publicationDetails/biblio?II=2\&ND=3\&adjacent=true\&locale=en_EP\&FT=D\&d ate $=19910223 \& \mathrm{CC}=\mathrm{SU} \& \mathrm{NR}=1629828 \mathrm{~A} 1 \& \mathrm{KC}=\mathrm{A} 1$.

[17] Girin OB (1998) Nonconventional X-ray diffraction techniques for coating characterization. Solidification Warrendale: The Minerals, Metals \& Materials Society, 161-169.

[18] Montgomery DC (2001) Design and Analysis of Experiments, 5th ed., John Wiley \& Sons, New York.

[19] Girin OB, Proshenko YO, Kalinushkin EP (2000) Texture of electrodeposited copper coatings, granular structure and surface morphology. Textures and Microstructures 34:171-179. https://doi:10.1155/TSM.34.171.

[20] DSTU GOST 9.303. Unified system of protection against corrosion and aging. Metallic and non-metallic inorganic deposits. (In Russian). 